\title{
Revisiting spontaneous Raman scattering for direct oxygen atom quantification
}

Citation for published version (APA):

van de Steeg, A. W., Vialetto, L., Silva, A. F., Peeters, F. J. J., van den Bekerom, D. C. M., Gatti, N., Diomede, P., van de Sanden, M. C. M., \& van Rooij, G. J. (2021). Revisiting spontaneous Raman scattering for direct oxygen atom quantification. Optics Letters, 46(9), 2172-2175. https://doi.org/10.1364/OL.424102

Document status and date:

Published: 01/05/2021

DOI:

10.1364/OL.424102

Document Version:

Publisher's PDF, also known as Version of record

Document license:

Taverne

Please check the document version of this publication:

- A submitted manuscript is the version of the article upon submission and before peer-review. There can be important differences between the submitted version and the official published version of record.

People interested in the research are advised to contact the author for the final version of the publication, or visit the DOI to the publisher's website.

- The final author version and the galley proof are versions of the publication after peer review.

- The final published version features the final layout of the paper including the volume, issue and page numbers.

Link to publication

\footnotetext{
General rights rights.

- You may freely distribute the URL identifying the publication in the public portal. please follow below link for the End User Agreement:

www.umlib.nl/taverne-license

Take down policy

If you believe that this document breaches copyright please contact us at:

repository@maastrichtuniversity.nl

providing details and we will investigate your claim.
}

Copyright and moral rights for the publications made accessible in the public portal are retained by the authors and/or other copyright owners and it is a condition of accessing publications that users recognise and abide by the legal requirements associated with these

- Users may download and print one copy of any publication from the public portal for the purpose of private study or research.

- You may not further distribute the material or use it for any profit-making activity or commercial gain

If the publication is distributed under the terms of Article $25 \mathrm{fa}$ of the Dutch Copyright Act, indicated by the "Taverne" license above, 


\title{
Revisiting spontaneous Raman scattering for direct oxygen atom quantification
}

\author{
A.W. van de Steeg ${ }^{1}$, L. Vialetto ${ }^{1}$, A.F. Silva ${ }^{1}$, F.J.J. Peeters ${ }^{1}$, D.C.M. van \\ Den BeKerom ${ }^{2}$, N. Gatti ${ }^{1,3}$, P. Diomede ${ }^{4}$, M.C.M. VAN De SANDEN ${ }^{1}$, G.J. VAN \\ ROOIJ ${ }^{1,4 *}$ \\ ${ }^{1}$ DIFFER, De Zaale 20, 5612AJ, Eindhoven, The Netherlands \\ ${ }^{2}$ Combustion Research Facility, Sandia National Laboratories, Livermore, CA 94550, USA \\ ${ }^{3}$ Università degli Studi di Trento, Dipartimento di Fisica, Via Sommarive 14, I-38123 Povo-Trento, Italy \\ ${ }^{4}$ Faculty of Science and Engineering, Maastricht University, Paul Henri Spaaklaan 1, 6229 GS Maastricht, The Netherlands \\ *Corresponding author: g.vanrooij@maastrichtuniversity.nl
}

In this letter the counterintuitive and largely unknown Raman activity of oxygen atoms is evaluated for its capacity to determine absolute densities in gases with significant 0 -density. The study involves $\mathrm{CO}_{2}$ microwave plasma to generate a self-calibrating mixture and establish accurate cross-sections for the ${ }^{3} \mathbf{P}_{2} \leftrightarrow{ }^{3} \mathbf{P}_{1}$ and ${ }^{3} \mathbf{P}_{2} \leftrightarrow{ }^{3} \mathbf{P}_{0}$ transitions. The approach requires conservation of stoichiometry, confirmed within experimental uncertainty by a 1D fluid model. The measurements yield $\sigma_{\mathrm{J}=2 \rightarrow 1}=5.27 \pm_{\text {sys: } 0.53}^{\text {rand } 0.17} \times 10^{-31} \mathrm{~cm}^{2} / \mathrm{sr}$ and $\sigma_{\mathrm{J}=2 \rightarrow 0}=2.11 \pm_{\text {sys: } 0.21}^{\text {rand: } 0.06} \times 10^{-31} \mathrm{~cm}^{2} / \mathrm{sr}$ and the detection limit is estimated to be $1 \times 10^{15} \mathrm{~cm}^{-3}$ for systems without other scattering species.

\section{Introduction}

Spontaneous Raman scattering has not gained much attention as an oxygen atom diagnostic since Raman activity is generally perceived to be possible only in molecular systems and is hence unexpected in oxygen atoms. However, in this work, we show that this technique can be a powerful addition to existing gas phase oxygen detection diagnostics, as it provides excellent spatial resolution and straightforward quantification.

Oxygen radicals play an important role in many fields, from thin film treatment [1] to combustion [2], the upper atmosphere [3] or plasma chemistry [4]. In thin film treatment, oxygen atoms are important due to their reactivity on surfaces [1] and have an important effect on film conformality and reachable aspect ratio. In flames, oxygen radicals play a role in the light emission and in the inhibition of soot-formation through the combustion of aromatic compounds [2]. In the upper atmosphere, oxygen atoms fulfill a crucial role in the heat balance and participate in the creation and destruction of ozone [3]. For plasma chemistry, the reactive oxygen radicals can be used for surface sterilization or water treatment [4]. Surface sterilization using plasma is gaining increasing attention in the medical fields, while water plasma-water treatment could be an innovative chlorinefree water purification method. Oxygen atoms also play crucial role in the energy efficiency of air and $\mathrm{CO}_{2}$ plasma. These processes have an increasing environmental interest, the first as sustainable alternative to the Haber-Bosch and Ostwald nitrogen fixation processes [5], the latter for $\mathrm{CO}_{2}$ utilization technologies [6].

In all these examples the rates of many important reaction pathways are controlled by $\mathrm{O}$-atoms, indicating that O-detection is crucial for increasing understanding and optimization in these important and emerging fields. However, easily quantifiable diagnostics are scarce.

Frequently applied 0-atom diagnostic techniques are two-photon laser-induced fluorescence (TALIF), actinometry, NO titration or threshold-ionization mass-spectrometry, direct VUV absorption and cavity ringdown [7]. While there's certainly no lack of options, each of these diagnostics comes with their own challenges and shortcomings, e.g. lack of spatial resolution (VUV absorption, actinometry, NO-titration), temporal resolution (CRDS), or both (NO titration, TI-MS). In addition, quantification is often challenging due to poorly known cross-sections and/or quenching rates as indicated by Booth et al. [7].

Given this, it is surprising that Raman scattering is not used more often for quantitative oxygen detection. Raman scattering, while having lower sensitivity than for instance TALIF, is significantly easier to quantify and thus more applicable in systems with large 0-densities. Additionally, it allows for simultaneous detection of Raman active molecular species and the rotational temperature. 

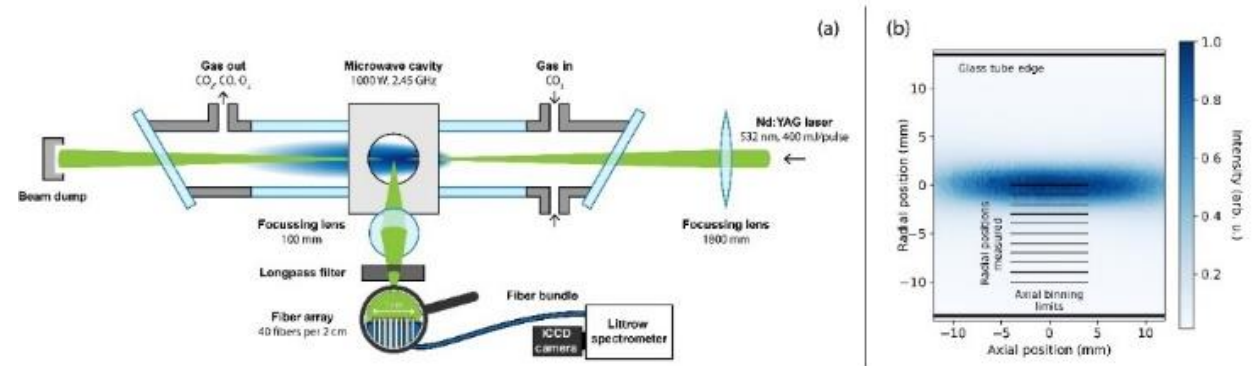

Fig. 1: The experimental setup combines a Raman scattering setup with a plasma reactor. (a) Plasma is ignited in a quartz tube inserted in a microwave cavity with tangentially injected $\mathrm{CO}_{2}$. Raman scattered light, produced with a $532 \mathrm{~nm}$ YAG laser focused into the center of the waveguide, is transferred with a linear fiber array to a Littrow spectrometer. Spatially resolved measurements are enabled by translating the plasma reactor radially. (b) photograph of $\mathrm{CO}_{2}$ plasma in which the sampled voxels are indicated.

Unfortunately, cross-sections values of the two Raman transitions, ${ }^{3} \mathrm{P}_{2} \leftrightarrow{ }^{3} \mathrm{P}_{1}$ and ${ }^{3} \mathrm{P}_{2} \leftrightarrow{ }^{3} \mathrm{P}_{0}$, at 158 and $226 \mathrm{~cm}^{-1}[8]$ are not unambiguously available. Experimental values were reported by Dasch \& Bechtel [8] in 1981 and $a b$-initio calculations were carried out by Sharma in 2004 [9] and 2005 [10]. However, these cross sections exhibit a spread of a factor four and thus a firm basis for quantitative Raman measurements is yet lacking.

The purpose of the present letter is threefold. Firstly, it reports new measurements of the cross-section values. Secondly, it demonstrates a novel cross-section measurement scheme in the self-calibrating system of a high temperatures plasma discharge. Thirdly, the sensitivity and applicability of Raman scattering for oxygen atom quantification is highlighted in $\mathrm{CO}_{2}$ and air, where the detection limit is determined in different background scattering conditions.

\section{Experimental method}

The oxygen atom spontaneous Raman cross-section is evaluated in $\mathrm{CO}_{2}$ microwave discharge, which provides a large range of oxygen atom concentrations. Power densities of up to $10 \mathrm{GW} / \mathrm{m}^{3}$ [11] drive neutral gas temperatures up to $7000 \mathrm{~K}$ and result in thermal dissociation of $\mathrm{CO}_{2}$ into $\mathrm{CO}$ and $\mathrm{O}$. Local conservation of stoichiometry and detectability of all species with Raman scattering makes the $\mathrm{CO}_{2}$ microwave self-calibrating. The O-Raman cross section can then be inferred as:

$$
\sigma_{\mathrm{O}}=\frac{P_{\mathrm{O}}}{n_{\mathrm{O}}}=\frac{P_{\mathrm{O}}}{P_{\mathrm{CO}} / \sigma_{\mathrm{CO}}-2 P_{\mathrm{O}_{2}} / \sigma_{\mathrm{O}_{2}}}, \quad \text { eq. } 1
$$

here, $P_{i}$ and $\sigma_{i}$ are the total scattering intensity and cross-section of species $i$, respectively, which are considered in more detail in [12], and conservation of stoichiometry determines $n_{\mathrm{O}}=n_{\mathrm{CO}}-2 \cdot n_{\mathrm{O}_{2}}$.

The details of the experimental layout have been reported elsewhere [13,14]. Briefly, laser scattering is implemented in a microwave plasma reactor, as is schematically shown in Fig. 1 Microwaves (700 W input power, $2.45 \mathrm{GHz}$ ) are launched into a waveguide to ignite plasma in a $10 \mathrm{l} / \mathrm{min}$ flow of $\mathrm{CO}_{2}$ or dry air through a $27 \mathrm{~mm}$ inner diameter quartz tube. Frequency doubled Nd:YAG (SpectraPhysics GCR-230, $400 \mathrm{~mJ}$ per pulse) laser light is focused in the center of the plasma. Scattered light is collected from the focal point and relayed with a linear fiber array. A sharp-edge longpass filter (Semrock RazorEdge 532nm) attenuates stray and Rayleigh scattered light. Spectral analysis is performed with a custom built $1 \mathrm{~m}$ focal-distance spectrometer $(1800 \mathrm{l} / \mathrm{mm}$ grating, $50 \mu \mathrm{m}$ entrance slit, $0.012 \mathrm{~nm} /$ pixel dispersion) equipped with a gated camera (Princeton Instruments PI-MAX4, $40 \mathrm{~ns}$ gate-width). Radial motion of the plasma reactor is provided by a translation stage to access both plasma core and periphery with Raman scattering.

The light from the central 20 fibers is binned to increase signal-to-noise. This corresponds to $8 \mathrm{~mm}$ in the plasma center, a small distance compared to the gradients of temperature and/or densities. The sampled voxels are indicated in the plasma emission photograph in Fig. 1(b) for the most inhomogeneous case studied: a contracted $\mathrm{CO}_{2}$ plasma at 0.150 bar and $700 \mathrm{~W}$ input power. The emission profile shows no gradients present in emission over the axial binning limit. Moreover, splitting the Raman images in $1 \mathrm{~mm}$ increments gives no differences apart from an increase in noise level. These two considerations make the binning a valid approach to increase sensitivity.

Details of the spectral analysis and synthetic spectrum generation are reported in the supplementary information.

\section{Results}

The spectra are collected in the core of a $\mathrm{CO}_{2}$ plasma at 0.1 bar and a near-atmospheric air plasma at 0.6 bar. The results of these measurements and fitted spectra are shown in Fig. 2.

The ratio between the cross-sections of the two atomic transitions follows from these spectra. Its value aligns well with the one predicted on basis of the Racah coefficients $[9,10]$ :

$$
\frac{\sigma_{J=2 \rightarrow 1}}{\sigma_{J=2 \rightarrow 0}}=2.5 .
$$


Absolute cross-section values are inferred from measurements in $\mathrm{CO}_{2}$ at 0.15 bar. Temperatures in the bright filament-like core (plasma image of Fig. 1(b)) exceed $6000 \mathrm{~K}$, while the periphery has negligible spontaneous plasma emission and much lower temperatures. The high and low temperature regions, in turn, correspond to a background to the 0 -atoms that consists mostly of $\mathrm{CO}$ or mostly of $\mathrm{O}_{2}$ and $\mathrm{CO}_{2}$ respectively.
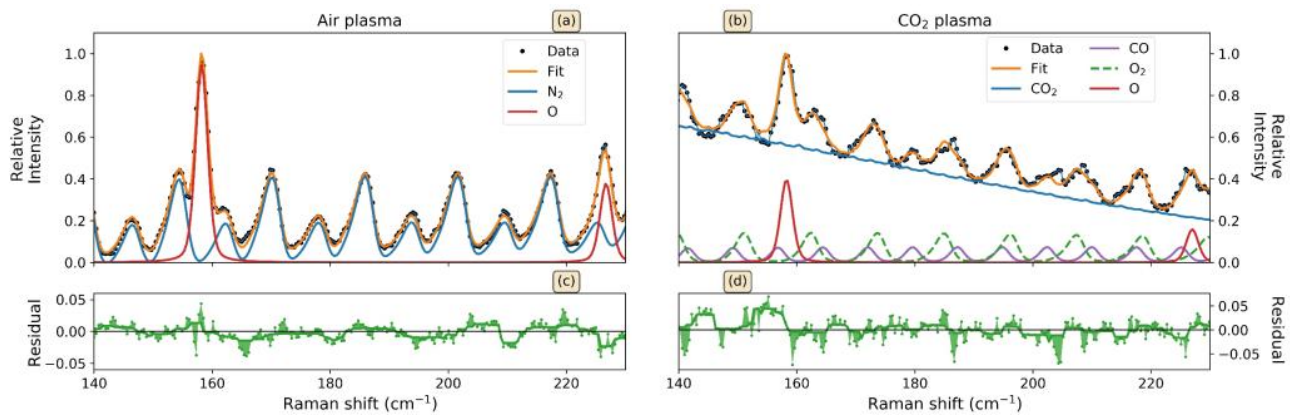

Fig. 2: Measured and fitted Stokes rotational Raman spectra (a) and (b) and residual (c) \& (d).

Fig. 3 shows the detailed results of the cross-section determination for different radial positions. The oxygen Raman crosssections can be calculated within $20 \%$ fitting error for most radial positions. In the supplementary information we discuss the correctness of this error estimate. First, we argue that species other than considered in Fig. 3, namely metastable states and carbon atoms, have negligible densities. Also, deviations from local conservation of stoichiometry can be a source of error in determining the oxygen Raman cross-sections. A 1:2 C to $\mathrm{O}$ ratio is assumed to determine the density of $\mathrm{O}$ atoms from the $\mathrm{CO}$ and $\mathrm{O}_{2}$ densities. A priori, one would worry about preferential diffusive transport of the heavier species $\mathrm{CO}, \mathrm{CO}_{2}$ and $\mathrm{O}_{2}$ compared to atomic oxygen. Thereby, this could cause a deviation from the 1:2 stoichiometric ratio of C:O. A 1D fluid model was developed to estimate the influence of demixing. It incorporates the main chemistry and transport processes and takes as input the gas temperature (from Raman) and power-density (inferred from plasma emission images) and returns species number densities and transport parameters. Two transport models are compared: Stefan-Maxwell multicomponent diffusion and simplified turbulent diffusion. Deviations in C:0 ratio up to respectively $8 \%$ and 1\% can occur, where significantly better overlap in species fraction is seen using the turbulent model. Additional results and further details of the model are presented in the supplementary information. The modeling results confirm stoichiometry is largely conserved and possible deviations are captured in the systematic error.

The systematic error is also comprised of uncertainty in the rotational Raman cross-sections of $\mathrm{CO}$ and $\mathrm{O}_{2}$. The polarizability anisotropies proposed in Klarenaar et al. [12] are based on calibrations with pure $\mathrm{O}_{2}$ and CO compared with $\mathrm{N}_{2}$. The absolute value of $\mathrm{N}_{2}$ is in turn taken as the average of the values of Penney [15] and Bogaard [16], in which a systematic error could exist. The total systematic error is taken as $10 \%$ to incorporate both uncertainty in stoichiometric ratio and $\mathrm{N}_{2}$ anisotropy.

Having addressed these possible sources of error we infer the cross-sections of the Raman lines of O-atoms to be:

$$
\begin{aligned}
& \sigma_{J=2 \rightarrow 1}=5.27 \pm_{\text {sys: } 0.53}^{\text {rand } 0.17} \times 10^{-31} \mathrm{~cm}^{2} / \mathrm{sr}, \\
& \sigma_{J=2 \rightarrow 0}=2.11 \pm_{\text {sys: } 0.21}^{\text {rand: } 0.06} \times 10^{-31} \mathrm{~cm}^{2} / \mathrm{sr},
\end{aligned}
$$

where in the error notation a distinction is made between systematic error from the stoichiometry and polarizability and the random measurement error from the fitting routine. The cross-sections values and their random uncertainties result from a $0^{\text {th }}$ order least squares fitting of the cross sections measured between 0 and $5 \mathrm{~mm}$. The cross sections from 6 to $10 \mathrm{~mm}$ were not considered in this fit since the $\mathrm{CO}_{2}$ signal becomes much larger than the 0-lines at larger radii, limiting the sensitivity for an accurate cross-section determination. Nonetheless, we note that all measured cross-section values are consistent with proposed values of eq. 3 , showing that the determination of the cross section is not dependent on gas temperature or background species.

The proposed cross-section is compared with literature values for the different plasma regions in Fig. 3(a), showing good overlap with the experimental value of Dasch \& Bechtel [8]. A last point of 

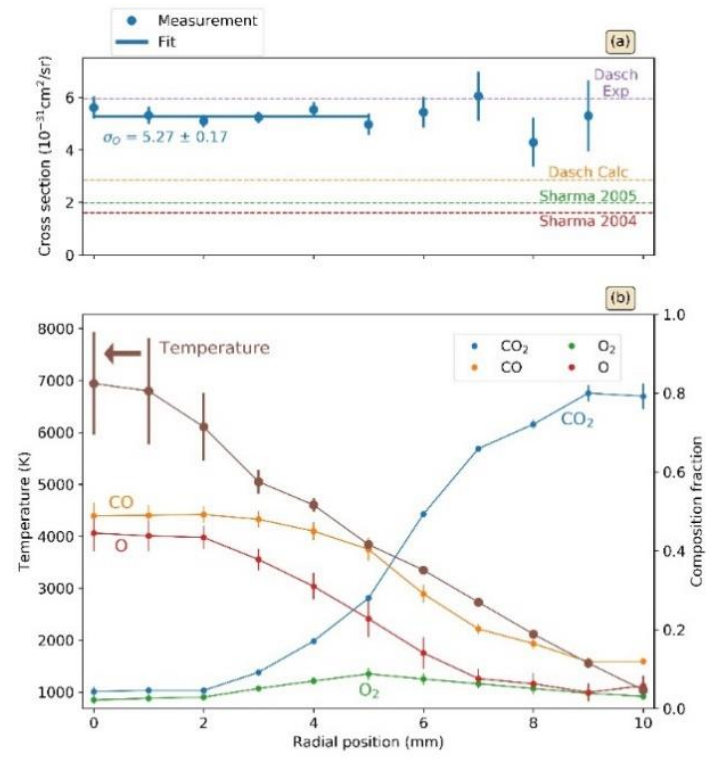

Fig. 3: (a) Measured cross-section $\left(\sigma_{\mathrm{J}=2 \rightarrow 1}\right)$ values for different radial positions, the mean of those values and the values available in literature. (b) Assessment of the validity of this method, showing a large temperature range where the cross-section is determined, both with $\mathrm{CO}_{2}$ fully dissociated and with $\mathrm{CO}_{2}$ present. Values up to $\mathrm{r}=5 \mathrm{~mm}$ are used for the cross-section determination, with $\mathrm{r}>5 \mathrm{~mm}$ the $\mathrm{O}$-atom signal strength becomes too low compared with the other gases and the accuracy drops.

comparison with literature considers the polarization-dependence of 0-Raman scattering. Calculated cross-sections in all considered works predict a depolarized (perpendicular to laser polarization) cross-section of the same order of magnitude as the polarized (following laser polarization) one [8-10]. In the results of Fig. 2 and Fig. 3 no polarizer is used, yet upon placing a polarizer and detecting the depolarized Raman, all 0-signature disappears. Therefore, we conclude the cross-section posed in Fig. 3 to belong to the polarized signal, while the depolarized cross-section is posed to be at least an order of magnitude smaller.

Having established the cross-section values, we estimate the detection limits for three situations: a case with no molecular Raman scattered light, a case with background scattering of $\mathrm{CO}_{2}$ and $\mathrm{O}_{2}$ and a case with $\mathrm{C}_{2}$ non-resonant LIF. These three situations are highlighted in Fig. 4.

In the first case, a gas with no other scattering species present, the detection limit is as low as $1 \times 10^{15} \mathrm{~cm}^{-3}$ for the used system as shown in Fig. 4(a). This is the density at which point the 0 -signal

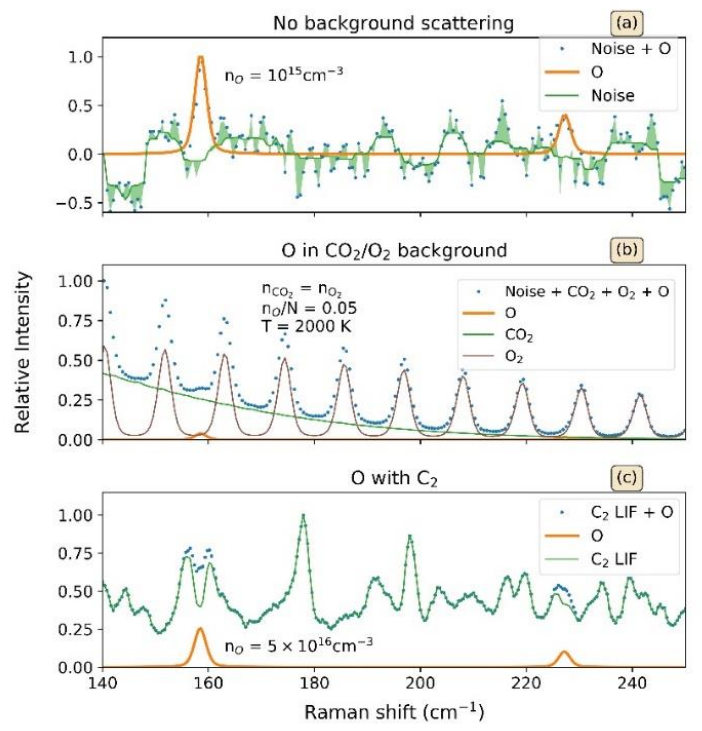


Fig. 4: Illustration of detection limits for (a) no background scattering, (b) $\mathrm{O}$ in a molecular background and (c) $\mathrm{O}$ in a $\mathrm{C}_{2}$ containing environment. Noise is taken as darknoise of the camera, the molecular spectra are synthetic and $\mathrm{C}_{2}$ emission is recorded in the center of a 0.25 bar, $700 \mathrm{~W} \mathrm{CO}_{2}$ plasma.

falls below the typical noise level of the camera. Decreasing this limit

could be achieved by shifting the laser to lower wavelengths or by increasing the numerical aperture of the system. Sharma theorizes a best-case detection limit of $10^{11} \mathrm{~cm}^{-3}$ for a specifically designed apparatus applied in the upper atmosphere [10] .

In the case with molecular species present the detection limit can best be given as a fraction, which in the case of a $\mathrm{CO}_{2} / \mathrm{O}_{2}$ mixture is established around $5 \%$.

Fig. 4(b) illustrates how the molecular Raman signal obfuscates the 0-Raman at a 20:1 fraction. This value can be different for other molecular systems. The higher spectral resolution and $\mathrm{S} / \mathrm{N}$ ratio of coherent techniques, such as coherent anti-stokes Raman scattering (CARS) can more easily resolve the $O$ lines in background scattering species, thus allowing for a more sensitive detection $[17,18]$.

The third case, with $\mathrm{C}_{2}$ present, is more problematic. The strong $\mathrm{LIF}$ of $\mathrm{C}_{2}$, excited by the laser, can be orders of magnitude stronger than the Raman signal $[14,19]$. This has an effect in for instance $\mathrm{CO}_{2}$ microwave plasma with $\mathrm{p}>0.2 \mathrm{bar}$, in combustion research or in dry reforming of methane. A typical $\mathrm{C}_{2}$ LIF spectrum, with camera gate just 40 ns after laser shot, is shown in Fig. 4(c). In $\mathrm{C}_{2}$ containing systems the detection limit will be higher, estimated for this plasma condition at $5 \times 10^{16} \mathrm{~cm}^{-3}$. This limit can be decreased by shifting the laser wavelength to the infrared, where the $\mathrm{C}_{2}$ LIF is no longer present but cross-sections decrease, by applying 0 -atom CARS to generate a coherent beam and reduce the omnidirectional fluorescence, or in a synergistic approach with TALIF. Combining TALIF and O-atom Raman could yield the best solution, since the much more sensitive TALIF could be absolutely calibrated using 0-atom Raman, removing the need for absolute calibration with Xe, which itself suffers from poorly established cross-section values [7].

\section{Conclusion}

We have recalibrated the cross-section values for atomic oxygen Raman scattering and demonstrated its applicability for quantitative measurements. Straightforward quantification and simultaneous detection of molecular concentrations and the rotational temperature are the main advantages compared with other diagnostics. In effect, O-atom Raman has been re-invented as a powerful diagnostic for a wide range of applications.

\section{References}

1. K. Arts, M. Utriainen, R. L. Puurunen, W. M. M. Kessels, and H. C. M. Knoops, J. Phys. Chem. C 123, 27030-27035 (2019).

2. Ö. L. Gülder, Combust. Flame 101, 302-310 (1995).

3. T. G. Slanger and R. A. Copeland, Chem. Rev. 103, 4731-4765 (2003).

4. A. Fridman, Plasma Chemistry, 1st ed. (Cambridge University Press, 2008).

5. B. S. Patil, Q. Wang, V. Hessel, and J. Lang, Catal. Today 256, 49-66 (2015).

6. D. C. M. van den Bekerom, J. M. P. Linares, T. Verreycken, E. M. van Veldhuizen, S. Nijdam, G. Berden, W. A. Bongers, M. C. M. van de Sanden, and G. J. van Rooij, Plasma Sources Sci. Technol. 28, (2019).

7. J.-P. Booth, A. Chatterjee, O. Guaitella, J. Santos Sousa, D. Lopaev, S. Zyryanov, T. Rakhimova, D. Voloshin, Y. Makelevich, N. D’Oliveira, and L. Nahon, Plasma Sources Sci. Technol. 29, (2020).

8. C. J. Dasch and J. H. Bechtel, Opt. Lett. 6, 36 (1981).

9. R. D. Sharma, J. Geophys. Res. Sp. Phys. 109, 1-6 (2004).

10. R. D. Sharma and P. D. Dao, J. Atmos. Solar-Terrestrial Phys. 67, 1519-1523 (2005).

11. A. J. Wolf, T. W. H. Righart, F. J. J. Peeters, W. A. Bongers, and M. C. M. van de Sanden, Plasma Sources Sci. Technol. 29, (2019).

12. B. L. M. Klarenaar, M. Grofulović, A. S. Morillo-Candas, D. C. M. Van Den Bekerom, M. A. Damen, M. C. M. Van De Sanden, O. Guaitella, and R. Engeln, Plasma Sources Sci. Technol. 27, (2018).

13. N. den Harder, D. C. M. Van den Bekerom, R. S. Al, M. F. Graswinckel, J. M. Palomares, F. J. J. Peeters, S. Ponduri, T. Minea, W. A. Bongers, M. C. M. van de Sanden, and G. J. van Rooij, Plasma Process. Polym. 14, 1-24 (2017).

14. A. van de Steeg, T. Butterworth, D. van den Bekerom, A. Silva, R. van de Sanden, and G. van Rooij, Plasma Sources Sci. Technol. 29, (2020).

15. C. M. Penney, R. L. St. Peters, and M. Lapp, J. Opt. Soc. Am. 64, 712-716 (1974).

16. M. P. Bogaard, A. D. Buckingham, R. K. Pierens, and A. H. White, J. Chem. Soc. Faraday Trans. 1 Phys. Chem. Condens. Phases 74, $3008-3015$ (1978).

17. R. E. Teets and J. H. Bechtel, Opt. Lett. 6, 458 (1981).

18. D. Escofet-Martin, A. O. Ojo, J. Collins, N. T. Mecker, M. Linne, and B. Peterson, Opt. Lett. 45, 4758-4761 (2020).

19. P. E. Bengtsson and M. Aldén, Combust. Sci. Technol. 77, 307-318 (1991). 